\title{
Optimization of Ensilage Total Mixed Fiber (TMF) with Additive and Incubation Periods Differences
}

\author{
A. Imsya ${ }^{1}$, Yuanita Windusari $^{2}$, and Riswandi ${ }^{1}$ \\ ${ }^{1}$ Animal Science Department, Faculty of Agriculture, Universitas Sriwijaya \\ ${ }^{2}$ Biology Science Department, Faculty of Mathematics and Natural Science, Universitas Sriwijaya
}

\begin{abstract}
This study aims to evaluate the effect of different types of additives and incubation periods for optimization of Total Mixed Fiber (TMF) silage. The method used in this study is randomized experimental design. The factorial pattern consists of 2 factors : additive type and incubation time. The treatment consists of Factor A type of additive: $\mathrm{A} 1=$ TMF ensilage with $7 \mathrm{~g}$ sodium diacetate $(\mathrm{SDA}) / \mathrm{kg}$ TMF $\mathrm{A} 2=\mathrm{TMF}$ ensilage with 10x105 cfu lactic acid bacteria / kg TMF. Factor B incubation time $\mathrm{B} 1=$ ensilage with 21 days incubation time, $\mathrm{B} 2=$ ensilage with 30 days incubation time and $\mathrm{B} 3$ = ensiles with 45 days incubation time. The parameters measured are evaluation of nutritional value based on proximate analysis and Van soest. The result of this research indicates that there is an interaction between the types of additives and the duration of incubation in the ensilage optimization of total mixed fiber (TMF). In this study, it is found that the use of sodium diacetate gives the best results in the optimization of TMF silage until the incubation time of 45 days. The contents of TMF silage nutritional value with sodium diacetate (SDA) $7 \mathrm{~g} / \mathrm{kg}$ TMF as additive and 45 days incubation time are $83.79 \%$ dry matter, $86.62 \%$ organic matter, $12.65 \%$ crude protein, $17 \%$ crude fiber, $8.07 \%$ crude fat, $68.65 \% \mathrm{NDF}, 58.78 \% \mathrm{ADF}, 56 \%$ cellulose $34,9.87 \%$ hemicellulose and $7.56 \%$ lignin
\end{abstract}

\section{Introduction}

Ensilage is a major forage conservation method, lactic acid bacteria (LAB) convert carbohydrates dissolved in water into lactic acid (AL) under anaerobic conditions. As a result, the $\mathrm{pH}$ decreases and feeding becomes durable. The success of the ensiling process relies heavily on the existing LAB on forage, and in general to improve the quality of silage can be done with the application of inoculants. The efficiency of LAB inoculants may be strongly influenced by the temperature in the silage[1]. Most commercial LAB inoculants are often little or even useful for silage under low temperature conditions[2]. The inoculation effect of lactic acid bacteria depends on many factors such as material properties, LAB characteristics and environmental temperature[3]. Most bacteria, a decrease in temperature lead to temporary transient cell capture, where protein synthesis is generally highly impeded, and low temperatures affect viability and acidification of bacteria [4]

Direct acidification of silage through organic acids causes a rapid decrease in $\mathrm{pH}$ and inhibits the growth of undesirable bacteria, which results in reduced nutrient loss [5]. 
However, organic acids are difficult to handle because of their strong odor, safely organic acid salts have been proposed as alternative additives for silage[6]. Sodium diacetate (SDA), an acetate derivative and food preservative, consisting of sodium acetate and acetic acid, it has proven effective for the growth inhibition of enterobacteria and yeast [7]. SDA is an effective microbial inhibitor and used as an antibacterial agent to extend incubation time of the silage[8]. The application of SDA decreases the $\mathrm{pH}$ of silage with the lowest $\mathrm{pH}$ in the use of SDA $7 \mathrm{~g} / \mathrm{kg}$ of material. The antimicrobial activity of SDA is reflected in the lower population of enterobacteria, yeast, fungi and clostridia, resulting in lower propionate, butoate, ethanol, ammonia $\mathrm{N}$ and lower levels of dry matter in silage added with SDA. The addition of SDA to $7 \mathrm{~g} / \mathrm{kg}$ fresh weight in Alfalfa silage can maintain stability more than 9 days after harvesting under humid and hot environmental conditions [9]. This study aims to optimize ensilage of total mixed fiber with additive and incubation time which is different.

\section{Materials and Methods}

Total Mixed Fiber ensilage is optimized with different additives. The method used in this study is randomized experimental design. The factorial pattern consists of 2 factors : additive type and incubation time. The treatment consists of Factor A type of additive: A1 = TMF ensilage with $7 \mathrm{~g}$ sodium diacetate (SDA) / $\mathrm{kg}$ TMF A2 $=\mathrm{TMF}$ ensilage with $10 \times 10^{5} \mathrm{cfu}$ lactic acid bacteria $/ \mathrm{kg}$ TMF. Factor $\mathrm{B}$ incubation time $\mathrm{B} 1=$ ensilage with 21 days incubation time, $\mathrm{B} 2=$ ensilage with 30 days incubation time and B3 = ensiles with 45 days incubation time

Ensiling procedure TMF : $20 \%$ Palm oil fronds $+20 \%$ rice straw $+20 \%$ swamp grass (Imsya et al., 20150) chopped into approximately $1.5 \mathrm{~cm}$ particle size, and then ensiled with Sodium Diacetat and Lactyc acid bacteria. About $1 \mathrm{~kg}$ treated TMF was packed into plastic laboratory silos (1-L capacity, $9.5 \mathrm{~cm}$ diameter $\times 18.7 \mathrm{~cm}$ height.), followed by sealing with two screw tops (internal and external). Six replicated silos per treatment are made and stored at ambient temperature $\left(32^{\circ} \mathrm{C}\right.$ to $\left.37^{\circ} \mathrm{C}\right)$. All silage are opened on $21 \mathrm{~d}, 30 \mathrm{~d}$ and $45 \mathrm{~d}$ after ensiling, 6 silos for each treatment are sampled for fermentation quality analysis. The parameters measured are evaluation of nutritional value based on proximate analysis and Van soest. The data are analyzed statistically in accordance with the design used to know the effect of treatment continued with Duncan's Multi Range Test.

\section{Results and Discussions}

Table 1. Proximate analysis of TMF silage with SDA and LAB additives in different incubation

\begin{tabular}{|c|c|c|c|c|c|c|}
\hline \multirow{2}{*}{ Nutrient } & \multicolumn{2}{|c|}{ 21-day Incubation } & \multicolumn{2}{c|}{ 30-day Incubation } & \multicolumn{2}{c|}{ 45-day Incubation } \\
\cline { 2 - 7 } & SDA & LAB & SDA & LAB & SDA & LAB \\
\hline Dry Matter & $89.59 \mathrm{c}$ & $87.12 \mathrm{~b}$ & $84,50 \mathrm{a}$ & $85.65 \mathrm{~b}$ & $83.79 \mathrm{a}$ & $82.79 \mathrm{a}$ \\
\hline Organic Matter & $88.62 \mathrm{a}$ & $87.54 \mathrm{a}$ & $86.59 \mathrm{~b}$ & $85.39 \mathrm{c}$ & $86.62 \mathrm{~b}$ & $80.90 \mathrm{~d}$ \\
\hline Crude Protein & $14.60 \mathrm{a}$ & $14.44 \mathrm{a}$ & $14.22 \mathrm{a}$ & $13.06 \mathrm{~b}$ & $12.65 \mathrm{~b}$ & $11.62 \mathrm{c}$ \\
\hline Coarse Fiber & $28.35 \mathrm{a}$ & $28.48 \mathrm{a}$ & $28.06 \mathrm{a}$ & $25.07 \mathrm{c}$ & $27.17 \mathrm{~b}$ & $23.54 \mathrm{~d}$ \\
\hline Crude Fat & $12.56 \mathrm{a}$ & $9.84 \mathrm{~b}$ & $11.21 \mathrm{a}$ & $10.63 \mathrm{a}$ & $8.07 \mathrm{~b}$ & $8.64 \mathrm{~b}$ \\
\hline
\end{tabular}

Note : different superscripts on the same row indicates significantly different treatment effect $(\mathrm{P}<0.05)$

Based on statistical analysis, it is found that the use of sodium diacetate additive and lactic acid bacteria for the optimization ensilage of total mixed fiber (TMF) has a significantly different effect $(\mathrm{P}<0.05)$ on the content of nutritional values with different incubation periods (Table 1). In each parameter, it is found that the use of SDA and LAB during the incubation 
period of 21 days has a significantly different effect on the nutritional value of dry matter, organic matter and crude fat but it does not significantly influence crude protein and crude fiber content. During the 30-day incubation period, the results of the use of SDA and LAB has significantly different effect $(\mathrm{P}<0.05)$ on the value of dry matter, organic matter, crude protein and crude fiber but it does not give a significant effect $(\mathrm{P}>0.05)$ on the value of crude fat. Increased incubation time until 45 days using SDA and LAB which have the same dose in the previous incubation period gives results where the value of dry material and crude fat does not indicate a significant difference $(\mathrm{P}>0.05)$, but it gives a significantly different effect $(\mathrm{P}<0.05)$ in the content of organic material, crude protein and crude fiber.

Lactic acid bacteria with a dose of $10^{5} \mathrm{cfu}$ used as additives in this study has a positive effect on the nutritional value until the incubation period of 21 days. The addition of TMF silage incubation until the 45 th day with LAB additive indicate a decrease in nutrient content. This is due to the proliferation of LAB in silage media requiring nutrition, so that some of the TMF nutrients will be overhauled by lactic acid bacteria to fulfill their activity needs. [10] states that during the silage process, degradation of nutrients by microbes such as lactic acid bacteria changes protein (proteolysis) into NPN compounds (Non nitrogenous proteins) and amino acids and structural carbohydrates are degraded into microbial energy sources. [11] also states that the release of sugar during the ensilage fermentation process is the result of hydrolysis from structural carbohydrates such as cellulose, hemicellulose and pectin.

The use of sodium diacetate $7 \mathrm{~g} / \mathrm{kg}$ TMF is able to optimize the process of total mixed fiber silage (TMF) until the incubation period of 45 days. This is viewed by a decrease in nutritional value that is not too large from the incubation period of 21 days to 45 days. It is different from the use of additive LAB. There is a decrease in nutritional value with an incubation period of up to 45 days. Sodium diacetate can be used as a preservative additive in silage because sodium diacetate is a source of acetate acid which can control and inhibit harmful microorganisms. [9] states that sodium in acetate in the silage process will be ionized into a source of acetic acid. Acetate acid is an effective substance to inhibit the development of undesirable microorganisms during the silage process. The antimicrobial process caused by acetate acid occurs because of the lipopilic process, acetic acid is able to penetrate into the microbial plasma so that it disrupts microbial metabolism. [7]. Antimicrobial activity can be reflected by the low population of enterobacterial, mold, fungus, and clostridia in alfalfa silage with sodium diacetate additive in the incubation period of up to 60 days [9].

Table 2. Van Soest Analysis of TMF silage with SDA and LAB additives in different incubation

\begin{tabular}{|c|c|c|c|c|c|c|}
\hline \multirow{2}{*}{$\cdot$} & \multicolumn{2}{|c|}{ 21-day incubation } & \multicolumn{2}{c|}{ 30-day Incubation } & \multicolumn{2}{c|}{ 45-day Incubation } \\
\cline { 2 - 7 } & SDA & LAB & SDA & LAB & SDA & LAB \\
\hline NDF & $74.14 \mathrm{a}$ & $71.24 \mathrm{ab}$ & $69.69 \mathrm{~b}$ & $68.96 \mathrm{~b}$ & $68.65 \mathrm{~b}$ & $66.41 \mathrm{c}$ \\
\hline ADF & $60.37 \mathrm{a}$ & $60.01 \mathrm{a}$ & $59.58 \mathrm{a}$ & $58.27 \mathrm{~b}$ & $58.78 \mathrm{a}$ & $56.19 \mathrm{c}$ \\
\hline Cellulose & $35.25 \mathrm{a}$ & $36.91 \mathrm{a}$ & $34.77 \mathrm{a}$ & $33.37 \mathrm{~b}$ & $34.56 \mathrm{a}$ & $31.65 \mathrm{~b}$ \\
\hline Hemicellulose & $13.77 \mathrm{a}$ & $11.23 \mathrm{~b}$ & $10.11 \mathrm{~b}$ & $10.69 \mathrm{~b}$ & $9.87 \mathrm{~b}$ & $10.22 \mathrm{~b}$ \\
\hline Lignin & $7.38 \mathrm{~b}$ & $9.08 \mathrm{a}$ & $7.41 \mathrm{~b}$ & $5.48 \mathrm{c}$ & $7.56 \mathrm{~b}$ & $4.64 \mathrm{c}$ \\
\hline
\end{tabular}

Note : different superscripts on the same row indicate significantly different treatment effects $(\mathrm{P}<0.05)$

Based on statistical analysis, it is found that the use of sodium diacetate additive and lactic acid bacteria to optimize mixed fiber (TMF) total encylase gives a significantly different effect $(\mathrm{P}<0.05)$ on fiber content with different incubation periods (Table 2$)$. During the incubation period of 21 days, the use of additives LAB and sodium diacetate indicates almost the same effect on the content of NDF, ADF and cellulose but it gives different effects on hemicellulose and lignin content. The same effect is given during the 30-day incubation period by LAB and SDA additives for NDF and hemicellulose content, while the ADF, cellulose and lignin contents indicates different effects. During the 45-day incubation period 
the effect of SDA additives has a different effect on LAB for the content of NDF, ADF, Cellulose and lignin, but it gives the same effect on hemicellulose content.

The use of SDA at a dose of $7 \mathrm{~g} / \mathrm{kg}$ as an additive in TMF silage can relatively maintain the fiber content until the incubation period of 45 days, especially for the content of ADF, cellulose and lignin while the content of N DF and hemicellulose relatively decreased. The use of LAB at a level of $10^{5} \mathrm{cfu} / \mathrm{kg}$ TMF for silage processes results in a decrease in fiber content with an incubation period of up to 45 days. This is because in the silage process, carbohydrate degradation occurs in silage by lactic acid bacteria. According to [12], in the ensylase process, plants are broken down into flying fatty acids, namely lactic acid, acetate acid, butyric acid, carbonic acid and alcohol in small amounts. In addition, in the silage process, there is a hemiselusase change occuring through 3 stages. namely the degradation of the plant hemicellulase enzyme itself, degradation by the enzyme hemicellulase by bacteria, and hydrolysis by organic acids produced during the fermentation process. Duration of incubation affects the content of fiber content. This is caused by a factor: The absence of oxygen is from silage, plant respiration, water content, silage-making factor, additive and incubation time [13].

\section{Conclusions}

There is an interaction between the types of additives and the duration of incubation in the ensilage optimization of total mixed fiber (TMF). In this study, it is found that the use of sodium diacetate gives the best results in the optimization of TMF silage until the incubation time of 45 days. The content of TMF silage nutritional with sodium diacetate (SDA) $7 \mathrm{~g} / \mathrm{kg}$ TMF as additive and 45 days incubation time are $83.79 \%$ dry matter, $86.62 \%$ organic matter, $12.65 \%$ crude protein, $17 \%$ crude fiber $27,8.07 \%$ crude fat, $68.65 \%$ NDF, $58.78 \%$ ADF, $56 \%$ cellulose $34,9.87 \%$ hemicellulose and $7.56 \%$ lignin.

\section{References}

1. Weinberg ZG, Szakacs G, Ashbell G, Hen Y. J. Appl Microbiol 90 (2001)

2. Liu Q, Chen M, Zhang J, Shi S, Cai Y. J. Anim Sci J 83 (2012)

3. Zhang JG, Kawamoto H, Cai Y. J. Anim Sci J 81 (2010)

4. Song S, Bae DW, Lim K, Griffiths MW, Oh S. J. Int J Food Microbiol 191 (2014)

5. Cazzato E, Laudadio V, Corleto A, Tufarelli V. J. Sci Food Agric 91 (2011)

6. Oladosu Y, Rafii MY, Abdullah N, et al.Fermentation quality and additives: a case of rice straw silage (Biomed Res Int, 2016)

7. Danner H, Holzer M, Mayrhuber E, Braun R. J. Appl Environ Microb 69 (2003)

8. Shockey W, Heinrichs A, Weiss W, Conrad H. J. Prod Agric 3 (1990)

9. Yuan, XJ., Aiyou Wen., Seare. T.D, Jian.W and Tao.S.Effects of sodium diacetate on the fermentation profile, chemical composition and aerobic stability of alfalfa silage, (2017)

10. Filya, I., J. Dairy Sci. 86 (2003)

11. McDonald, P, A. R. Hendenon \& S. J. E. Hercn, The Biochemistry of Silage. Chalcombe publications (Cenlerbury UK, 1991)

12. Ensminger, M. E and Olentine, C. G, Feeds and Nutrition Complete (The Ensminger Publishing Company, Clovis, California, U.S.A. Filya 1978) 
13. Coblentz, W. Principles of Silage Making (University Of Arkansas. Payetteville, 2003) 